East African Medical Journal Vol. 80 No. 7 July 2003

A NEW CLASSIFICATION OF OSTEOMYELITIS FOR DEVELOPING COUNTRIES

B.A. Solagberu, MBBS, FWACS (Ortho), Consultant Orthopaedic and Trauma Surgeon, Department of Surgery, University of Ilorin Teaching Hospital, Ilorin, Nigeria, P.O. Box 4377, Ilorin 240001, Nigeria

\title{
A NEW CLASSIFICATION OF OSTEOMYELITIS FOR DEVELOPING COUNTRIES
}

\author{
B.A. SOLAGBERU
}

\begin{abstract}
Background : The term osteomyelitis (OSM) was first coined by Nelaton in 1844. Waldvogel et al, Cierny-Mader, May et al classifications of OSM from developed countries and Meier et al's from Nigeria have been described.

Objective: This new classification was developed to highlight significant pathology seen in developing countries not covered by existing classifications.

Design: A prospective study.

Setting: University of Ilorin Teaching Hospital, Ilorin, Nigeria.

Subjects: All OSM patients treated from January 1998 to June 2000.

Main outcome measures: Age, sex, clinical features, radiographs and treatment offered were analysed. Five stages were recognised: stage 0 (potential OSM with bone contamination), stage I (early or acute OSM), stage II (intermediate OSM with subperiosteal abscess), stage III (late or chronic OSM with sequestrum and subdivided into IIIa 'curable', IIIb 'controllable', IIIc 'complicated'). Stage IV (compound OSM) with joint involvement: IVa, if anatomical and IVb if physiological. Patients' haemoglobin $(\mathrm{Hb})$ status is added to the staging, for example stage II (Hb SS).

Results: All 271 patients comprising 198 males and 73 females (M: F= 2.7: 1) with age range 2-48 years (mean $29.4 \pm 12.2$ ) were studied. Only 93 patients had Hb genotype done; only 42 had Hb S. The stage $\mathrm{O}$ had 184 patients (120 open fractures and 64 bone operations). Stage I had nine patients, stage II 19 patients, stage III 51 patients and stage IV eight.

Conclusions: This new staging incorporates pre-emptive OSM seen in developing countries where certain practices, if unchecked lead to OSM. The severity of OSM featuring florid disease not common in the developed world, and for which existing classifications did not accommodate, is included.
\end{abstract}

\section{INTRODUCTION}

According to Wilensky(1), Nelaton probably coined the term osteomyelitis (OSM) in 1844. Bone infection, potential or actual, ever since then has remained a serious clinical problem for the developing(2,3) and the developed(4,5) countries. Advances in understanding and control of OSM have led to the development of several classifications to guide treatment and research. While all the classifications (Waldvogel et al (6), Cierny-Mader(7), May et al(4), emanating from the developed world were aimed at global usage, increasingly the sheer differences in disease spectrum worldwide have continued to provoke a classification system suitable for the circumstances of the developing countries. Meier et al(2) in 1993 proposed a classification for developing countries to address these peculiarities. This present study from a developing country is a product of experience with OSM that was not adequately accommodated by Meier et al's(2) classification.

Osteomyelitis can be classified using at least five parameters: duration, hence, acute (AOSM) or chronic (COSM); pathogenesis (haematogenous, post-traumatic, true contiguous spread, or surgery); location or site (tibia, femur, spine, foot); extent (size of defect) or host status (normal host, compromised host, adult, child or infant).(5) Waldvogel et al's classification(6) described in 1970 deals with pathogenesis of haematogenous OSM. CiernyMader classification(7) combines anatomical description of OSM with physiological host response. It was developed in 1985. May et al(4) described the staging of posttraumatic tibial OSM into five in 1989. Meier et al's classification(2) described in 1993 for developing countries was a practical approach to classification and treatment where there are limited resources. The peculiarities of the present classification is the pre-emptive nature as seen in stages $\mathrm{O}$ (pre-invasion), II (intermediate), III a and b (curable and controllable COSM) and IV (compound COSM with joint involvement) which were not reflected in all the previous classifications but are seen in significant proportions in our practice. Osteomyelitis is commoner and presents much later in developing countries than in the developed $(2,8,9)$. This new classification should encourage rational planning of treatment and prevention of progression of disease. It should also help in prognosticating and comparing results of treatment. 


\section{MATERIALS AND METHODS}

Data collected prospectively on patients, seen by the author, who were at risk of developing OSM or who already had OSM at the University of Ilorin Teaching Hospital Ilorin, Nigeria were analysed as they became available and used in classifying OSM into five stages $\mathrm{O}$ to $1 \mathrm{~V}$. The ages, sex, clinical, radiological and operative findings of the patients were noted. A preliminary report covering the period from January 1998 to June 2000 is presented.

The spectrum of OSM treated were characterised as potential OSM (pre-invasion or bone contamination) if there was a risk of developing OSM as in open fractures or operations on bone including open reduction and internal fixation of fracturesStage O. Actual OSM was also characterised based on pathogenesis into early or acute OSM Stage 1, intermediate OSM Stage II, late or chronic OSM Stage III and compound OSM Stage IV (Tables 2A-2E).

Stage III is further subdivided into three ( $\mathrm{a}, \mathrm{b}, \mathrm{c}$ : curable, controllable and complicated OSM respectively). Curable refers to OSM located in such bones as can have an affected segment completely excised as in the fibula and mid portions of the radius and ulna in children. Within weeks of excision, healthy bone unites the 'gap' fracture left behind (Figures 1a-2d).

\section{Figure 1a}

Chronic Osteomyelitis (with long segment of sequestrum) involving mid-segments of fibula in a 4-year old child with Haemoglobin $S+S$

Figure 1b

Immediate post operative period after excision. The coiled tube is a vacuum drain

\section{Figure 1c}

Healing of the gap fracture after 12 weeks

Controllable refers to diffuse type of Cierny-Mader where bone debridement and grafts impregnated with antibiotics are used to achieve control of bone infection for a variable number of years. Complicated OSM refers to pathological fracture, infected non-union and malunited COSM. Stage IV Compound OSM where infection has affected the joint is in two parts: anatomical and physiological joint involvement. Anatomical involvement (IVa) means additional septic arthritis while a situation of chronic pyomyositis with fibrotic muscles lacking contractile properties leading to joint stiffness but without actual anatomical joint involvement represents the physiological type (IVb).

\section{Figure 2a}

Chronic Osteomyelitis of $(R)$ midsegment of the ulna with sequestrum and surrounding involucrum. The $(L)$ side showed proximal ulna osteomyelitis with protruding sequestrum

\section{Figure 2b}

Post operative excition of the $(R)$ ulna segment - to the right of the figure and debridement and sequestrectomy of the $(L)$ ulna - to the left of the figure 


\section{Figure 2c}

Healing of the gap fracture of the right ulna. The left ulna has no residual disease 12 weeks after

Figure 2d

Twenty weeks after operation fibrotic fibres that lack the contractile properties of normal muscle) and absence of joint movements but radiologically, the articular cartilage is preserved. (Table 2E). The high prevalence of haemoglobin $\mathrm{S}$ disease in our environment and the peculiar nature of OSM in such patients makes it necessary to add in parentheses the haemoglobin of the patient being staged. For example, stage $\mathrm{II}(\mathrm{Hb}$ SS) or stage III (Hb SC), stage IV (Hb AA) and so on and so forth. Therefore, the peculiar nature of sickle cell OSM(10-12) and the special anaesthetic requirements are focused on due to the staging formula. The patients have been followed up for a variable period of two to 20 months.

\section{RESULTS}

Two hundred and seventy one patients with potential or actual OSM were seen by the author from January 1998 to June 2000 . The age range was two years to 48 years (mean $29.4 \pm 12.2$, median 20.0 years). There were 198 males and 73 females $(\mathrm{M}: \mathrm{F}=2.7: 1)$. Haemoglobin genotype was available in only 93 patients. Forty two patients had haemoglobin $(\mathrm{Hb}) \mathrm{S}$ disease; $10 \mathrm{Hb} \mathrm{S}+\mathrm{S}$, six $\mathrm{Hb} \mathrm{S}+\mathrm{C}, 26 \mathrm{Hb} \mathrm{A}+\mathrm{S}$ while 51 were $\mathrm{Hb} \mathrm{A}+\mathrm{A}$.

The five stages classified showed Stage O with 184 patients, stage I of AOSM nine patients, stage II with intermediate OSM had 19, stage III had 51 patients with six patients in IIIa, 33 patients in IIIb and 12 in IIIc while stage IV compound OSM had eight patients, five anatomical (IVa) and three physiological (IVb).

\section{Table 1}

New staging for osteomyelitis for developing countries: Preliminary results with 271 patients

against potential pathogens in open reduction and internal fixation (ORIF) while wound toileting and/or skin grafting are done for overlying ulcers. Open fractures are covered with Povidone iodine, debrided and stabilised with Plaster of Paris and a window created for dressing or with external stabilising pins or fixation depending on the grade of fracture using Gustilo and Anderson's staging(10). Stage I OSM is also treated by antibiotics, culture-driven sulbactamampicillin 750-1500 mg 12 hourly or cefuroxime 750-1500 mg 12 hourly for four to six weeks. It is almost exclusively found among patients 15 years and younger presenting with a high-grade fever above $38.5^{\circ} \mathrm{C}$, limb swelling, localised tenderness and normal radiographs. Technicium scans are not routinely available in most places in the developing countries. Radiographs are done at 2weekly intervals to confirm good response to therapy, (Tables $2 \mathrm{~A}$ and 2B).When found among adults, stage I OSM is usually following post-operative infection with or without orthopaedic implant or in the immunocompromised. Stage II OSM is recognised on clinical, radiological and operative grounds, by the presence of fever, limb swelling and tenderness, radiographs showing periosteal thickening and operative finding of subperiosteal abscess. Treatment by minimal periosteal stripping and multiple drill holes, intravenous antibiotics for 14 days followed by oral drugs for four to six weeks is employed. (Table 2C). Stage III COSM has a somewhat long history, limb swelling with or without a discharging sinus. There is no associated fever but blood count showed leucocytosis, with lymphocytosis, high erythrocyte sedimentation rate (ESR), radiographs showing distortion of cortical-medullary architecture and variable presence of sequestrum, (Table 2D). Stage IV is OSM with joint involvement (additional septic arthritis) with distortion of articular cartilage in IV a. In IV b, clinical demonstration of taut muscles (guitar-string,

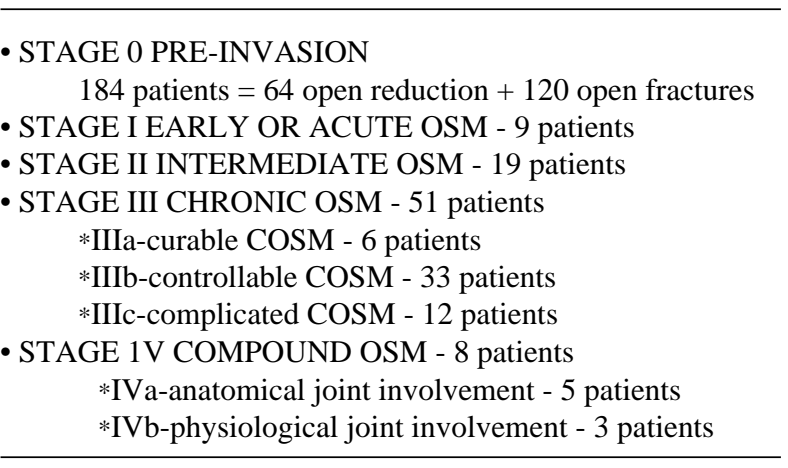

NB: The patient's haemoglobin genotype is added in parenthesis, for example stage II(Hb SS) or stage $\mathrm{O}(\mathrm{Hb} \mathrm{AA})$ or stage III $(\mathrm{Hb}$ $\mathrm{SC})$

Of the 184 stage 0 OSM, 64 were ORIF (14 humerus, 38 femur, 12 tibial and 120 open fractures: eight in femur, 77 tibial, 19 humerus and 16 radius and ulna fractures). Three stage 0 OSM from the ORIF group progressed to III b after 12 months. Eleven others from the open fracture group had worsened situation after nine months to stage IIIb, giving 14 patients who progressed from stage 0 to stage III. Follow up was poor as all the stage I OSM were lost to follow up. Two patients progressed to stage III b from stage II; nine were lost to follow up. There was no patient with further progression from stage III. 
Table 2 A Stage 0

\begin{tabular}{|c|c|c|c|c|}
\hline Stage & Nomenclature & Description & Examples & $\begin{array}{l}\text { Treatment } \\
\text { profile suggested }\end{array}$ \\
\hline $\mathrm{O}$ & Pre-invasion & $\begin{array}{l}\text { Bone contamination } \\
\text { by open fracture or } \\
\text { bone operation }\end{array}$ & $\begin{array}{l}\text { *Open fractures } \\
* \text { Open reduction of } \\
\text { closed fractures } \\
\text { *Ulcers overlying bone }\end{array}$ & $\begin{array}{l}\text { Prophylactic antibiotic } \\
\text { against suspected organisms } \\
\text { (Regular wound toileting } \\
\text { and / or skin grafting) }\end{array}$ \\
\hline \multicolumn{5}{|c|}{ Table 2 B Stage I } \\
\hline Stage & Nomenclature & Description & Examples & $\begin{array}{l}\text { Treatment } \\
\text { profile suggested }\end{array}$ \\
\hline I & $\begin{array}{l}\text { Early or Acute } \\
\text { Osteomyelitis }\end{array}$ & $\begin{array}{l}\text { Initial bone } \\
\text { involvement; but } \\
\text { bone is viable } \\
\mathrm{X} \text {-ray normal or } \\
\text { periosteal reaction }\end{array}$ & $\begin{array}{l}\text { *Acute } \\
\text { haematogenous OSM } \\
\text { *Post operative } \\
\text { infection with or } \\
\text { without implant }\end{array}$ & $\begin{array}{l}\text { Culture-driven antibiotics: } \\
\text { Sulbactam ampicillin } \\
\text { Ofloxacin } \\
\text { Cefuroxime }\end{array}$ \\
\hline \multicolumn{5}{|c|}{ Table 2 C Stage II } \\
\hline Stage & Nomenclature & Description & Examples & $\begin{array}{l}\text { Treatment } \\
\text { profile suggested }\end{array}$ \\
\hline II & $\begin{array}{l}\text { Intermediate } \\
\text { Osteomyelitis }\end{array}$ & $\begin{array}{l}\text { Infected and ischaemic } \\
\text { bone but salvageable } \\
\text { (clinically limb swollen+ } \\
\text { tender, high fever) } \\
\text { X-ray periosteal elevation }\end{array}$ & $\begin{array}{l}\text { *OSM with } \\
\text { sub-periosteal } \\
\text { abscess } \\
\text { especially in a } \\
\text { child }\end{array}$ & $\begin{array}{l}\text { Multiple drill holes, minimal } \\
\text { periosteal disruption during } \\
\text { operation } \\
\text { *IV antibiotics for 3-4 weeks } \\
\text { +oral for another } 3-4 \text { weeks }\end{array}$ \\
\hline
\end{tabular}

Table 2 D Stage III

\begin{tabular}{|c|c|c|c|c|}
\hline Stage & Nomenclature & Description & Examples & $\begin{array}{l}\text { Treatment } \\
\text { profile suggested }\end{array}$ \\
\hline III & $\begin{array}{l}\text { Late or } \\
\text { Chronic }\end{array}$ & $\begin{array}{l}\text { Various stages of } \\
\text { sequestrum formation }\end{array}$ & (a) Localized OSM in & (a)Excision of bone, curettage of \\
\hline (a) & OSM & (a) Curable OSM & $\begin{array}{l}\text { mid-segment of fibula or } \\
\text { radius or ulna in a child }\end{array}$ & periosteum in a child \\
\hline (b) & & (b)Controllable OSM & $\begin{array}{l}\text { (b) X-ray:Long/Large } \\
\text { sequestrum (Bone in } \\
\text { bone appearance) }\end{array}$ & $\begin{array}{l}\text { b)Saucerisation+sequestrectomy, } \\
\text { Muscle flaps, cancellous bone graft, } \\
\text { curettage, suture woud primarily } \\
\text { Papineu technique, Belfast procedure }\end{array}$ \\
\hline (c) & & (c)Complicated OSM & $\begin{array}{l}\text { (c) Pathological fracture, } \\
\text { infected non-union, } \\
\text { malunited chronic OSM }\end{array}$ & (c)As in (b) essentially \\
\hline
\end{tabular}

Table 2 E: Stage IV

\begin{tabular}{|c|c|c|c|c|}
\hline Stage & Nomenclature & Description & Examples & $\begin{array}{l}\text { Treatment } \\
\text { profile suggested }\end{array}$ \\
\hline IV & $\begin{array}{l}\text { Compound } \\
\text { chronic }\end{array}$ & $\begin{array}{l}\text { Chronic OSM with } \\
\text { joint involvement }\end{array}$ & $\begin{array}{l}\text { (a)Septic arthritis } \\
\text { complicating(long } \\
\text { bone)chronic OSM }\end{array}$ & $\begin{array}{l}\text { Open arthrotomy and } \\
\text { appropriate procedure for } \\
\text { OSM }\end{array}$ \\
\hline (a) & OSM & $\begin{array}{l}\text { (a) Anatomical } \\
\text { septic arthritis }\end{array}$ & & (b)No appropriate \\
\hline (b) & & (b) Physiological & $\begin{array}{l}\text { (b)Joint contactures } \\
\text { from fibrotic muscles }\end{array}$ & $\begin{array}{l}\text { satisfactory treatment } \\
\text { available, tendon release } \\
\text { being evaluated }\end{array}$ \\
\hline
\end{tabular}




\section{DISCUSSION}

Dissatisfaction with existing classification of diseases has always inevitably encouraged the development of new ones. Classification allows researchers to speak a uniform language globally in respect of a disease, relate treatment to different stages of disease, compare results of treatment and prognosticate on the outcome. When there is a new understanding of disease or a different spectrum is reported or special treatments are evolved, new classifications often become necessary and are described. A staging process, however, should be simple, easy to apply and must be logical. Preferably it should have universal application, except if its limitations are stated. This study attempts to satisfy all these requirements in the classification proposed and used.

In the developing countries, it has been shown that poverty and ignorance coupled with inadequate health facilities and personnel combine to ensure late reporting of OSM in the hospital $(2,3,10,13)$. Indiscriminate use of antibiotics obtained over the counter without prescription usually gave patients an illusion of treatment $(2,3)$. All these factors ensure that OSM in developing countries present in severe forms with florid disease. Additionally, these extensive bone infections receive inadequate surgical debridement due to a dearth of qualified personnel and great expense in procuring appropriate anti-microbials. It is not uncommon to find certain fractures being operated when it is obvious that the skill and facilities available to the general practice physician doing this are inadequate. The consequence of this is courting of OSM, which is completely avoidable. Many patients with open fractures are not routinely offered debridement and stabilisation. Gustilo(14) remarked that open fractures require emergency treatment, adequate debridement and wound irrigation. The treatment offered our patients often did not conform to this. emergency requirement for a variety of reasons including poor logistics. Whereas these realities are not common in developed countries, that they are regular features in our practice should encourage labelling these patients as potential candidates for OSM through a stage 0 disease, so that they will receive aggressive and emergency attention. Despite the efforts, some patients, 14 out of the $184(7.6 \%)$ stage 0 patients still progressed to higher stages of disease- stage 111 .

The stage I patients lost to follow up is reflective of common experience with OSM patients in the third world countries as Meier et al(2) recorded loss rate above $50 \%$. The absence of radiological signs in AOSM has been explained on the basis of the approximate 10 days it takes for complete mineralisation to occur(15). Additionally, alterations in radiographic density cannot be detected until there is a decrease of 35 to $50 \%$ in bone mineral content; hence, osseous changes are not seen until 10 to 14 days after onset of infection(15) Conversely, by the second week when periosteal reactions are seen coupled with soft tissue swelling as in stage II disease, carrying out multiple drill holes to relieve the high tension built up by pus in the rigid bone cage is desirable. When this pressure is not let out, development of sequestrum ensues by one or a combination of three mechanisms: pressure necrosis, septic embolus or sequestering of cortex by the subperiosteal abscess. At this stage, no antibiotics given to the patient would reach the bone, hence, the need for surgical debridement to control the infection at this phase (stage IIIb).

This series describes some three children who had excision of a segment of "dispensable" bone that can be excised as in a child with generally good healing of the resultant gap fracture.Figures 2 and 3. None of these has recurred in the 18 to 20 months of follow up. Evidently, patients with infected non-union, malunited osteomyelitic bone or pathological fracture need special consideration in stage IIIc (Table $2 \mathrm{D}$ ). The stage IVa was offered the appropriate operations for the involved bones and then an arthrotomy to clear the joint sepsis. The entire plan is to leave alone the silent ankylosed joint. Our treatment plan has been to control the bone and joint sepsis.

It is clear that this classification is more comprehensive of the variety of OSM seen in the developing countries as it accommodates all the pathologic processes seen (natural history of OSM, unlike that by Meier $e t$ $a l$ 's(2) four stages of acute, acute with X-rays, chronic localised and chronic systemic. Theirs did not include the stage 0 common in the third world. Cierny-Mader's classification(7) needlessly did not reckon with stage 0 as practices in the developed world did not warrant for it, nor the advanced stages of IIIc and IV a and IV b, which are exclusively seen in areas of late and neglected disease. Waldvogel et al's classification(6) of OSM using aetiology only: haematogenous, contiguous focus, osteomyelitis associated with vascular insufficiency and vertebral OSM is descriptive pathologically but not reflecting severity or therapy.

There is a high proportion of sickle cell disease in Nigeria $(9,12)$. Such patients have certain peculiarities with their OSM; hence, a parenthesis is placed after the stage of OSM indicating the patients' haemoglobin genotype. The immediate advantage of this new classification of OSM for developing countries is the comparison of results of treatment in one centre from time to time or between different centres. Further research is continuing on this, however, the usefulness of this staging has prompted this preliminary report.

\section{ACKNOWLEDGEMENT}

To the Director, Ilorin University Teaching Hospital for permission to publish this manuscript.

\section{REFERENCES}

1. Wilensky, A.O. The mechanism and pathogenesis of acute osteomyelitis. Am. J. Surg. NS. 1927; 3:281-289.

2. Meier, D.E., Tarpley, J.L., Olaolorun, D.A., Howard, C.R. and Price, C.T. Haematogenous Osteomyelitis in the Developing World: A Practical Approach to Classification 
and Treatment with Limited Resources. Contemp. Orthop. 1993; 26:495-505.

3. Oyemade, G.A.A., Dawodu, A.H. and Olusanya, A.O.A. Osteomyelitis in Nigerian Children (a review of 40 cases). J. Trop. Med. Hyg. 1977; 80:183-186.

4. May, J.W.Jr., Jupiter, J.B., Wieland, A.J. and Byrd, H.S. Clinical Classification of Post-Traumatic Tibial Osteomyelitis. J. Bone Joint Surg. 1989;71-A:1422-1428.

5. Mader, J.T., Ortiz, M. and Calhoun, J.H. Update on the Diagnosis and Management of Osteomyelitis. Clin. Padiatr. Med. Surg. 1996; 13:701-724.

6. Waldvogell, F.A., Medoff, G. and Swartz, M.N. Osteomyelitis: a review of clinical features, therapeutic considerations and unusual aspects.

N. Eng. J. Med. 1970; 282:198-206, 206-266, 316-322.

7. Cierny, G. 3rd, Mader, J.T. and Pennick, J.J. A clinical staging system of adult osteomyelitis. Contemp. Orthop. 1985;10:17-37.

8. Nade, S. Acute Haematogenous Osteomyelitis in Infancy and Childhood. J. Bone Joint Surg. 1983; 65-B:109-119.
9. Solagberu, B.A., Olatunji, P.O., Adekanye, A.O. and Onile, B.A. Chronic Osteomyelitis in Ilorin-a two year review. Afr. J. Clin. Experim .Microbiol. 2000; 1:125-133.

10. Gustilo, R.B. and Anderson, J.T. Prevention of Infection in the treatment of 1,025 open fractures of long bones: retrospective and prospective analysis. J. Bone Joint Surg. 1976; 58-A:453-458.

11. Jellis, J.E. Haematogenous Osteomyelitis. Surgery. 1992; 10:145-148.

12. Adeyokunnu, A.A. and Hendrickse, R.G. Salmonella osteomyelitis in childhood: a report of 63 cases seen in Nigerian children of whom 57 had sickle cell anaemia. Arch. Dis. 1980; 55:175-184.

13. Ebong, W.W. and Oyemade, G.A.A. Acute Haematogenous Osteomyelitis in Nigeria.Trop. Geogr. Med. 1978;30:41461.

14. Gustilo, R.B. Use of antimicrobials in the management of open fractures. Arch. Surg. 1979; 114:805-808.

15. Bonakdar-pour, A. and Gaines, V.D. The Radiology of Osteomyelitis. Orthop. Clin. N. Amer. 1983; 14:21-37. 